\title{
A convenient one-pot synthesis of aryl amines from aryl aldoximes mediated by Koser's reagent
}

\author{
Harisadhan Ghosh, Arghya Baneerjee, Saroj Kumar Rout, and Bhisma K. Patel* \\ Department of Chemistry, Indian Institute of Technology Guwahati, \\ Guwahati, 781 039, Assam, India \\ E-mail: patel@iitg.ernet.in
}

\begin{abstract}
A simple and convenient procedure has been developed for the synthesis of aromatic amine by a one-pot reaction of aromatic aldoxime with hypervalent iodine(III) reagent [hydroxy(tosyloxy)iodo]benzene (HTIB, Koser's reagent), in an alkaline medium. The aldoxime reacts with Koser's reagent to form an intermediate hydroxamic acid, which then undergoes Lossen type rearrangement to produce the desired amine. Several amines have been prepared which otherwise are difficult to prepare, by the reduction of corresponding nitro compounds. The scopes and limitations of this transformation have been discussed.
\end{abstract}

Keywords: Hypervalent iodine, aldoxime, amine, Lossen rearrangement, hydroxamic acid, nitrile oxide

\section{Introduction}

Organic hypervalent iodine reagents have found diverse applications in synthetic organic chemistry because of their selectivity, efficiency, simplicity of use, commercial availability and most importantly, their environmentally benign character. ${ }^{1}$ Hypervalent iodine compounds are versatile but selective oxidants that have the added advantage of being biodegradable yielding low toxicity by-products. As an oxidants, hypervalent iodine(III) or $\lambda^{3}$-iodane reagents are widely recognized as an alternatives to highly toxic heavy metal oxidants such as lead, mercury and thallium based reagents. ${ }^{1}$ In addition to acting as an useful oxidizing agents, derivatives of hypervalent iodine reagent occupy an important place in the area of natural and synthetic organic chemistry because of its potential applications for the construction of carbon-heteroatom and carbon-carbon bonds. ${ }^{1,2}$ The Koser's reagent, [hydroxy(tosyloxy)iodo]benzene (HTIB) is an useful oxidizing agent for a range of organic substrates. ${ }^{3}$ The most typical reaction of HTIB is the functionalization of carbonyl compounds at the $\alpha$-carbon. ${ }^{4}$ Koser et al. described the 
Hofmann-type preparation of amines using HTIB, from long-chain aliphatic amides which are unreactive under normal Hofmann conditions. ${ }^{5}$

Our group has explored the thiophilicity of hypervalent iodine(III) reagent, (diacetoxyiodo)benzene (DIB), for various useful organic transformations. These include the preparation of $N$-acylureas from 1,3-disubstituted thioureas, ${ }^{6}$ isothiocyanates, ${ }^{7}$ cyanamides ${ }^{8}$ and various heterocycles ${ }^{7}$ from dithiocarbamic acid salts by an oxidative desulfurization strategy. Very recently, we have reported the oxidation of aldoximes to $\mathrm{N}$-acetoxy or $\mathrm{N}$-hydroxy amides mediated by hypervalent iodine(III) reagent DIB or HTIB. ${ }^{9}$ Aromatic amines are most common reagents in synthetic organic chemistry. Amines and their salts are used as antioxidants for rubber and roofing asphalt, stabilizers for cellulose nitrate explosives, protectants against damage from gamma radiation, developers in photography, flotation agents in mining, fabric softeners, in paper coating, and for solubilizing herbicides. Diamines such as 4,4'-dimethylene-dianiline (MDA) and 4,4'-methylene-bis-orthochloroaniline (MbOCA), are used in the production of epoxy resins and high performance polyurethanes respectively. Aromatic amines are also useful for the preparation of various azo dyes and drugs. ${ }^{10}$

Amines are conveniently prepared by the reduction of organonitro compounds using various reducing agents, ${ }^{11}$ including radical reduction of aromatic azides with triethylsilane ${ }^{12 a}$ etc. Very recently, they have been prepared by a palladium catalyzed coupling of ammonia and lithium amide with aryl halides. ${ }^{12 \mathrm{~b}}$ Another, convenient method for preparation of amine, is the coppercatalyzed couplings of aromatic boronic acids with aqueous ammonia at room temperature. ${ }^{13}$ Amines can also be prepared from various hydroxamic acid derivatives or $O$-activated hydroxamic acids through Lossen rearrangement. Recently, Hoshino et al. reported a novel base mediated rearrangement route for the preparation of aromatic amines without using any activating agent. ${ }^{14}$ Though the reported method is of high standard, but, it starts from hydroxamic acids which is relatively a uncommon starting material and difficult to synthesize.

\section{Results and Discussion}

In our earlier study, various aliphatic and aromatic aldoximes with the hypervalent iodine(III) reagents (diacetoxyiodo)benzene (DIB) or [hydroxy(tosyloxy)iodo]benzene (HTIB) mediated oxidation reactions gave, respectively, $N$-acetoxy or $N$-hydroxy amides in good yields. Although the expected nitrile oxide dimerized product oxadiazole- $N$-oxides reported to be formed with other oxidizing and hypervalent iodine reagents ${ }^{15}$ which is quite contrary to our observation. ${ }^{9}$ Subsequently, we developed a facile, convenient method to prepare hydroxamic acids from various aromatic and aliphatic aldoximes using Koser's reagent. ${ }^{9}$

In synthetic methodology, carrying out the multi steps reaction in one-pot is highly attractive because of higher yield of the desired product, less reaction time and thus can directly be started from simple, readily available starting materials avoiding loss of products in each step. Taking cues from the reported method of base mediated rearrangement of hydroxamic acids ${ }^{14}$ and our 
facile access of hydroxamic acid, ${ }^{9}$ we thought to develop a one-pot strategy to prepare amines directly starting from readily available aldoximes.

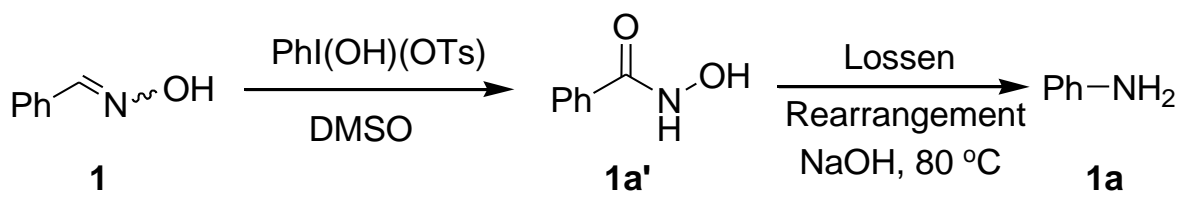

\section{Scheme 1}

In a typical reaction, HTIB (1.4 equiv.) was added to a stirred solution of benzaldehyde oxime 1 (1 equiv.) in DMSO at room temperature and the mixture was stirred for $30 \mathrm{~min}$. The reaction mixture was subsequently heated at $80^{\circ} \mathrm{C}$ for $1{ }^{\prime \prime} \mathrm{h} \mid "$ and the in situ generated hydroxamic acid 19' was then treated with sodium hydroxide ( $\mathrm{NaOH}, 1.5$ equiv.) and heating was continued for additional $1.5 \backslash$ 'hl" to yield aniline 1a (Scheme 1) in good yield. In the search of suitable solvent system for this one-pot rearrangement, the reaction was carried out using different solvents such as DMF, THF, DMA, 1,4-dioxane, DMSO and water. The isolated yields of the desired product after $3 \backslash " \mathrm{~h} \backslash "$ were $60 \%, 40 \%, 60 \%, 35 \%, 97 \%, 0 \%$ respectively. Thus, polar solvent DMSO was found to be the best among the solvents tested for this transformation an observation consistent with Hoshino et al. ${ }^{14}$

Formation of the amine (aniline) from benzaldehyde oxime $\mathbf{1}$ can be explained by the following mechanism (Scheme 2).

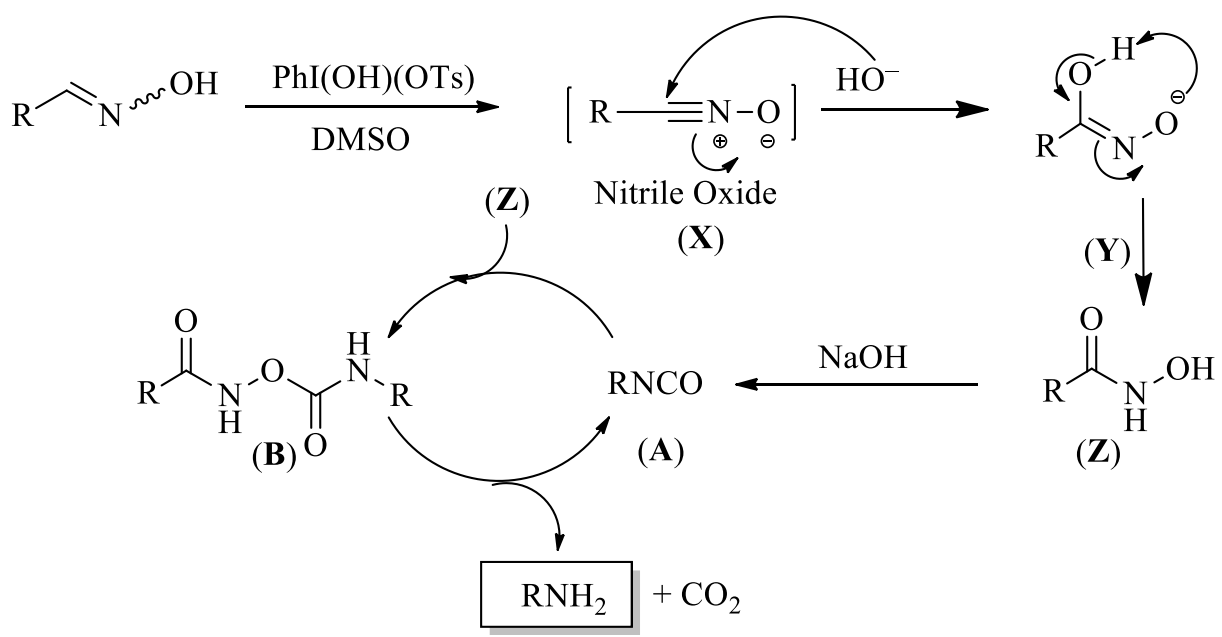

\section{Scheme 2}

According to this mechanism, the first step is the formation of hydroxamic acid (Z) through the nitrile oxide intermediate $(\mathbf{X})$, as has been reported by us. ${ }^{9}$ The in situ generated hydroxamic acid possibly undergoes base mediated Lossen rearrangement to form isocyanate (A). A very 
small amount of isocyanate $(\mathbf{A})$ is probably the reactive intermediate which initiates the reaction and the chain reaction continues. The isocyanate $(\mathbf{A})$ is attacked by hydroxamic acid $(\mathbf{Z})$ to generate $O$-carbamoyl hydroxamate $(\mathbf{B})$, the rearrangement of which gives aniline and regenerates isocyanate (A) (Scheme 2).

According to the proposed mechanism above (Scheme 2), the reaction should go with the addition of catalytic amount of base $(\mathrm{NaOH})$. The use of 0.05 equivalent of $\mathrm{NaOH}$ gave $80 \%$ yield of the amine 1a (Scheme 1) after $8 \mathrm{l} " \mathrm{~h} h "$. For faster conversion 1.5 equiv of $\mathrm{NaOH}$ was used for all the substrates. In the absence of any base, no aniline was formed. It should be mentioned here that, when the reaction was performed using $O$-acyl hydroxamic acid as the starting material, under the identical reaction condition, no amines were detected. This observation supports that the catalytic pathway is observed in the case of hydroxamic acid only (without an activating agent).

Due to the immense synthetic importance of amine, we applied this strategy to various aldoxime for the preparation of corresponding amine which otherwise are difficult to prepare by conventional nitration followed by the reduction. The versatility of the developed methodology has been explored through the preparation of various aromatic amines (Table 1). It has been observed that aromatic aldoximes having electron donating groups at any positions in an aromatic ring undergo facile transformation. Thus, aromatic amines possessing electron donating substituents such as Me, OMe, propargyloxy-, allyloxy- 2a - 10a, were prepared in excellent yield using the present methodology starting from aldoximes 2-10. The stability of other functional groups containing substituents such as alkynes $\mathbf{5 a}$ and alkenes $\mathbf{7 a}$, was also found to be compatible in the reaction giving the product in good yield. Amine having allyloxy- and propargyloxy- would be difficult to prepare by any other methods. The sensitive functional groups containing substrates such as allyloxy- or propargyloxy- neither tolerate the nitration condition not the reduction condition.

Amines bearing electron withdrawing substituents on the aromatic ring such as $\mathrm{Cl}, \mathrm{Br}, \mathrm{NO}_{2}$ at ortho and para position 11a-15a can be efficiently prepared from the corresponding aldoximes 11-15. Surprisingly aldoximes possessing either weakly electron withdrawing groups $(\mathrm{Br}, \mathrm{Cl})$ or strongly electron withdrawing group $\left(\mathrm{NO}_{2}\right)$ at the meta position, completely failed to form the corresponding amines. This observation is consistent with the literature reports which state that electron withdrawing substituents at meta position shows very low yield of corresponding amine or no product at all due to higher activation energy required to have for the rearrangement. ${ }^{16}$ This method was not successful for the preparation of aliphatic amines from their aldoximes. 
Table 1. Preparation of amine from aldoxime ${ }^{\mathrm{a}}$

(2)

${ }^{a}$ Reactions were monitored by TLC. ${ }^{b}$ Confirmed by IR, ${ }^{1} \mathrm{H}$ and ${ }^{13} \mathrm{C}$ NMR and comparison with authentic. ${ }^{\mathrm{c}}$ Isolated yield. 


\section{Conclusions}

In conclusion, we have demonstrated a hypervalent iodine(III) reagent HTIB mediated in situ generation of hydroxamic acids, followed by a base mediated rearrangement of a variety of aromatic aldoximes to amines in one-pot. This method is excellent for the preparation of electron rich aromatic amines from the corresponding aldoximes. The main advantages of the present method are preparation of unusual amines, the operational simplicity and efficiency which starts from the readily available aldoximes thus suitable for large scale reaction for the preparation of amines.

\section{Experimental Section}

\section{General procedure for preparation of $p$-toluidine (2a) from $p$-methylbenzaldehyde oxime (2)} A mixture of $p$-methylbenzaldehyde oxime $2(0.27 \mathrm{~g}, 2 \mathrm{mmol})$, Koser's reagent $(1.09 \mathrm{~g}, 2.8$ $\mathrm{mmol})$ in DMSO $(2 \mathrm{~mL})$ medium was stirred at room temperature for $30 \mathrm{~min}$ and then heated at $80^{\circ} \mathrm{C}$ for $1 \mathrm{~h}$. Base $\mathrm{NaOH}(3 \mathrm{mmol}, 0.12 \mathrm{~g}$ ) was added (after confirming the total conversion of to its corresponding hydroxamic acid by TLC) and heating was continued for another $1.5 \mathrm{~h}$. The mixture was admixed with water $(1 \mathrm{~mL})$ and extracted with ethylacetate $(2 \times 10 \mathrm{~mL})$. The ethylacetate layer was washed with water $(2 \times 2 \mathrm{~mL})$. The organic layer was dried over anhydrous sodium sulphate $\left(\mathrm{Na}_{2} \mathrm{SO}_{4}\right)$, filtered and evaporated under reduced pressure. The product so obtained was sufficiently pure, but for analytical data it was purified through a short column of basic alumina using (hexane / ethyl acetate, 6:4) as the eluent to yield the pure $p$ toluidine $\mathbf{2 a}(0.207 \mathrm{~g}, 97 \%)$.

\section{Spectral data of selected compounds}

3-Methoxy-phenylamine (4a). Liquid, ${ }^{1} \mathrm{H}$ NMR (400 MHz, $\left.\mathrm{CDCl}_{3}\right): \delta 3.6$ (br s, 2H), 3.74 (s, $3 \mathrm{H}), 6.23(\mathrm{~s}, 1 \mathrm{H}), 6.27(\mathrm{~d}, J=8.0 \mathrm{~Hz}, 1 \mathrm{H}), 6.32(\mathrm{~d}, J=8.0 \mathrm{~Hz}, 1 \mathrm{H}), 7.05(\mathrm{t}, J=8.0 \mathrm{~Hz}, 1 \mathrm{H}) .{ }^{13} \mathrm{C}$ NMR (100 MHz, $\left.\mathrm{CDCl}_{3}\right): \delta 55.2,101.2,104.1,108.1,130.3,147.9,160.9 . \mathrm{IR}(\mathrm{KBr}): 3363$, 2924, 2852, 1603, 1459, 1290, 1205, 1157, 1035, 799, 687, $515 \mathrm{~cm}^{-1}$.

3-Prop-2-ynyloxyphenylamine (5a). Liquid, ${ }^{1} \mathrm{H}$ NMR (400 MHz, $\left.\mathrm{CDCl}_{3}\right): \delta 2.5$ (s, 1H) 3.7 (br $\mathrm{s}, 2 \mathrm{H}), 4.6(\mathrm{~s}, 2 \mathrm{H}), 6.32(\mathrm{~s}, 1 \mathrm{H}), 6.4(\mathrm{~m}, 2 \mathrm{H}), 7.1(\mathrm{t}, 1 \mathrm{H}, J=8.0 \mathrm{~Hz}) \cdot{ }^{13} \mathrm{C}$ NMR $(100 \mathrm{MHz}$, $\left.\mathrm{CDCl}_{3}\right): \delta 55.9,75.5,78.9,102.2,104.9,108.9,130.3,147.9,158.9$. IR (KBr): 3650, 3366, 3289, 2924, 2120, 1603, 1490, 1375, 1288, 1157, 1032, 829, 761, $687 \mathrm{~cm}^{-1}$.

4-Allyloxyphenylamine (7a). Liquid, ${ }^{1} \mathrm{H}$ NMR (400 MHz, $\left.\mathrm{CDCl}_{3}\right)$ : $\delta 3.07$ (br s, $\left.2 \mathrm{H}\right), 4.37(\mathrm{~m}$, 2H), $5.17(\mathrm{~m}, 1 \mathrm{H}), 5.30(\mathrm{~m}, 1 \mathrm{H}), 5.96(\mathrm{~m}, 1 \mathrm{H}), 6.55(\mathrm{~d}, J=8.8 \mathrm{~Hz}, 2 \mathrm{H}), 6.68(\mathrm{~d}, J=8.8 \mathrm{~Hz}, 2 \mathrm{H})$. ${ }^{13} \mathrm{CNMR}\left(100 \mathrm{MHz}, \mathrm{CDCl}_{3}\right): \delta 69.7,116.1,116.5,117.5,133.9,140.3,151.9$. IR $(\mathrm{KBr}): 3347$, $3100,2926,2276,1615,1509,1232,1020,925,826 \mathrm{~cm}^{-1}$.

2,5-Dimethoxyphenylamine (8a). MP $80{ }^{\circ} \mathrm{C}$, (Lit. 80-81 $\left.{ }^{\circ} \mathrm{C}\right){ }^{17 a}{ }^{1} \mathrm{H}$ NMR $\left(400 \mathrm{MHz}, \mathrm{CDCl}_{3}\right): \delta$ $3.79(\mathrm{~s}, 3 \mathrm{H}), 3.82(\mathrm{~s}, 3 \mathrm{H}), 6.23(\mathrm{~d}, J=8.2 \mathrm{~Hz}, 1 \mathrm{H}), 6.31(\mathrm{~s}, 1 \mathrm{H}), 6.7(\mathrm{~d}, J=8.4 \mathrm{~Hz}, 1 \mathrm{H})$. 
${ }^{13} \mathrm{CNMR}\left(100 \mathrm{MHz}, \mathrm{CDCl}_{3}\right): \delta 42.7,55.4,100.9,100.5,113.2,128.8,140.7,149.9 . \mathrm{IR}(\mathrm{KBr})$ : $3357,3000,2938,2835,1618,1597,1513,1466,1265,1234,1164,1136,1025,951,836,806$, $762,704,620,547 \mathrm{~cm}^{-1}$.

3,4-Dimethoxyphenylamine (10a). MP $85{ }^{\circ} \mathrm{C}$, (Lit. 83-87 ${ }^{\circ} \mathrm{C}$ ) ${ }^{17 \mathrm{~b}}{ }^{1} \mathrm{H}$ NMR $\left(400 \mathrm{MHz}, \mathrm{CDCl}_{3}\right): \delta$ $3.72(\mathrm{~s}, 3 \mathrm{H}), 3.8(\mathrm{~s}, 3 \mathrm{H}), 6.24(\mathrm{~d}, J=8.8 \mathrm{~Hz}, 1 \mathrm{H}), 6.33(\mathrm{~s}, 1 \mathrm{H}), 6.69(\mathrm{~d}, J=8.8 \mathrm{~Hz}, 1 \mathrm{H})$. ${ }^{13} \mathrm{CNMR}\left(100 \mathrm{MHz}, \mathrm{CDCl}_{3}\right): \delta 55.7,56.3,102.1,102.3,111.5,137.5,142.05,154.5$. IR $(\mathrm{KBr})$ : $3461,3369,2941,1622,1520,1465,1312,1227,1037,952,838,788 \mathrm{~cm}^{-1}$.

\section{Acknowledgements}

B. K. P acknowledges support of this research from DST New Delhi (SR/S1/OC-79/2009) and CSIR 01(2270)/08/EMR-II. H.G and S.K.R thank CSIR for fellowships. Thanks are due to CIF IIT Guwahati for NMR spectra.

\section{References}

1. (a) Wirth, T.; Ochiai, M.; Zhdankin, V. V.; Koser, G. F.; Tohma, H.; Kita, Y. Topics in Current Chemistry: Hypervalent Iodine Chemistry- Modern Developments in Organic Synthesis, Spinger-Verlag, Berlin, 2002. (b) Varvoglis, A. Hypervalent Iodine in Organic Synthesis, Academic Press, London, 1997. (c) Stang, P ; Zhdankin, V. V. Chem. Rev. 1996, 96, 1123. (d) Varvoglis, A. Tetrahedron 1997, 53, 1179. (e) Zhdankin, V. V.; Stang, P. Chem. Rev. 2002, 102, 2523. (f) Zhdankin, V. V.; Stang, P. Chem. Rev. 2008, 108, 5299. (g) Ochiai, M. In Chemistry of Hypervalent Compounds; Akiba, K., Ed.; VCH Publishers: New York, 1999; Chapter 13, 359.

2. (a) Nicolaou, K. C.; Zhong, Y.-L.; Baran, P. S. Angew. Chem., Int. Ed. 2000, 39, 622. (b) Nicolaou, K. C.; Zhong, Y.-L.; Baran, P. S. Angew. Chem., Int. Ed. 2000, 39, 625. (c) Dohi, T.; Maruyama, A.; Minamitsuji, Y.; Takenaga, N.; Kita, Y. Chem. Commun. 2007, 1224.

3. (a) Koser, G. F. Aldrichimica Acta 2001, 34, 89. (b) Moriarty, R. M.; Vaid, R. K.; Koser, G. F. Synlett 1990, 365. (c) Varvoglis, A. The Organic Chemistry of Polycoordinated Iodine, VCH, New York, 1992. (d) Yusubov, M. S.; Wirth, T. Org. Lett. 2005, 7, 519.

4. (a) Varma, R. S.; Kumar, D.; Liesen, P. J. J. Chem. Soc., Perkin Trans. 1 1998, 4093. (b) Choi, O. K.; Cho, B. T. Tetrahedron: Asymmetry 2001, 12, 903. (c) Zhang, P.-F.; Chen, Z. C. Synth. Commun. 2001, 31, 415. (d) Lee, J. C.; Jin, Y. S. Synth. Commun. 1999, 29, 2769. (e) Lee, J. C.; Kim, S.; Shin, W. C. Synth. Commun. 2000, 30, 4271. (f) Goff, J. M.; Justik, M. W.; Koser, G. F. Tetrahedron Lett. 2001, 42, 5597.

5. Vasudevan, A.; Koser, G. F. J. Org. Chem. 1988, 53, 5158.

6. Singh, C. B.; Ghosh, H.; Murru, S.; Patel, B. K. J. Org. Chem. 2008, 73, 2924.

7. Ghosh, H.; Yella, R.; Nath, J.; Patel, B. K. Eur. J. Org. Chem. 2008, 6189. 
8. Ghosh, H.; Yella, R.; Ali, A. R.; Sahoo, S. K.; Patel, B. K. Tetrahedron Lett. 2009, 50, 2407.

9. Ghosh, H.; Patel, B. K. Org. Biomol. Chem. 2010, 8, 384.

10. International Union of Pure and Applied Chemistry 2009. "azo compounds". Compendium of Chemical Terminology Internet edition. Fennema, O.R.: Food Chemistry, 3rd edition, 1996.

11. (a) Zheng, Y.; Ma, K.; Wang, H.; Sun, X.; Jiang, J.; Wang, C.; Li, R.; Ma, J. Catal. Lett. 2008, 124, 268 and references cited therein. (b) Carruthers, W. Modern methods of organic synthesis, 2003, third edition, 421. (c) Bae, J. W.; Cho, Y. J.; Lee, S. H.; Yoon, C.-O. M.; Yoon, C. M. Chem. Commun. 2000, 1857.

12. (a) Benati, L.; Bencivenni, G.; Leardini, R.; Minozzi, M.; Nanni, D.; Scialpi, R.; Spagnolo, P.; Zanardi, G. J. Org. Chem. 2006, 71, 5822. (b) Shen, Q.; Hartwig, J. J. Am. Chem. Soc. 2006, 128, 10028.

13. Rao, H.; Fu, H.; Jiang, Y.; Zhao, Y. Angew. Chem., Int. Ed. 2009, 48, 1114.

14. Hoshino, Y.; Okuno, M.; Kawamura, E.; Honda, K.; Inoue, S. Chem. Commun. 2009, 2281.

15. Das, B.; Holla, H.; Mahender, G.; Banerjee; J.; Reddy, M. R. Tetrahedron Lett. 2004, 45, 7347.

16. Berndt, D. C.; Shechter, H. J. Org. Chem. 1963, 29, 916.

17. (a) Yi, H-P.; Shao, X-B.; Hou, J-L.; Li, C.; Jiang, X-K.; Li, Z-T. New J. Chem. 2005, 29, 1213. (b) Stuart, J. G.; Khora, S.; McKenney, J. D. Jr.; Castle, R. N. J. Heterocyclic Chem. 1987, 24, 1589. 